\title{
Performance of PEMFC with Platinum/Carbon Black Entrapped in a Chitosan Matrix
}

\author{
Nanthiya Hansupalak ${ }^{1,2}$, Kittitat Sodapak ${ }^{1}$, Sundara L. Ghatty ${ }^{3}$, Bobba Rambabu ${ }^{3}$ \\ ${ }^{1}$ Department of Chemical Engineering, Faculty of Engineering, Kasetsart University \\ Bangkok 10900, Thailand \\ fengnyh@ku.ac.th; Kitipat.s@gmail.com \\ ${ }^{2}$ Center for Advanced Studies in Industrial Technology, Faculty of Engineering, Kasetsart University \\ Bangkok 10900, Thailand \\ ${ }^{3}$ Solid State Ionics and Surface Science Laboratory, Department of Physics, Southern University and A\&M College, \\ Baton Rouge, LA 70813, USA \\ Lakki.lanka@gmail.com; Rbobba2015@gmail.com
}

\section{Extended Abstract}

This work demonstrates the potential use of chitosan, biopolymer, as a proton-conducting polymer for $\mathrm{H}_{2} / \mathrm{O}_{2} \mathrm{PEM}$ fuel cells. Platinum/carbon black catalysts $(\mathrm{Pt} / \mathrm{C})$ entrapped in epichlorohydrin-crosslinked chitosan are used to prepare the cathode electrocatalysts. The effects of the epichlorohydrin content $(0-12 \mathrm{~g})$, operating temperatures $\left(40-80{ }^{\circ} \mathrm{C}\right)$, and relative humidity $(50-100 \% \mathrm{RH})$ on performance of the fuel cells were investigated. A JEOL JEM-1400 transmission electron microscope was used to probe the morphology of samples. For membrane electrode assembly (MEA), the ink solution for the anode electrode consisted of isopropanol, deionized water, the Nafion solution, and the unmodified $\mathrm{Pt} / \mathrm{C}$ in an amount that yielded a platinum loading of $0.5 \mathrm{mg} \mathrm{cm}^{-2}$. The same recipe was used for the cathode except that the unmodified Pt/C was replaced by the same weight of the modified Pt/C. The performance of the MEA was evaluated after conditioning the MEA for $2 \mathrm{~h}$ at $0.5 \mathrm{~V}$ and $40{ }^{\circ} \mathrm{C}$ (i.e. steady state conditions) by using a Compact Fuel Cell Test System (model 850e; Scribner Associates, Inc.) controlled using the Fuel Cell ${ }^{\circledR} 3.9 \mathrm{c}$ software.

The results showed that the addition of epichlorohydrin up to $4 \mathrm{~g}$ yielded uniform distributions of chitosan coating on the carbon black support. The higher amounts of epichlorohydrin greater than $4 \mathrm{~g}$ gave nonuniform distribution and $\mathrm{Pt}$ clusters with larger size. This was due to the fact that epichlorohydrin chemically crosslinks chitosan chains [1]. Thus, the localized tight networks could induce more agglomeration of carbon black particles, generating larger Pt clusters as viewed by TEM. On the other hand, in case of a lower epichlorohydrin amount, the chitosan coating was more uniform throughout the sample, giving rise to the smaller agglomerates of carbon black particles. The performance of the fuel cells fabricated with the catalyst samples with higher epichlorohydrin content was notably poorer than that of the cells assembled with the catalysts with lower epichlorohydrin content. Curve fitting with theoretical equations revealed that the poor cell performance was ascribed to both larger activation and ohmic overvoltages, which suggests a slowing of the redox reaction rates and an increased resistance in the fuel cells, respectively. The high amounts of crosslinker generated the localized tight networks of chitosan, which resulted in thicker layers of chitosan that can totally block pores in the cathode layer, preventing the reactant gas from accessing the active sites. The results showed that $100 \% \mathrm{RH}$ could properly hydrates the fuel cell prepared in this current work, facilitating the mass transfer in the temperature range of $40-80{ }^{\circ} \mathrm{C}$. But the cell performance, irrespective of the type of catalyst used, became poorer when $\mathrm{RH}$ was less than $100 \%$. That is, even though the temperature enhanced the reaction rates and mass transfer, but it also caused the dehydration of the cell, as reported elsewhere [2]. Thus, it was concluded that the performance of the fuel cells fabricated in this work was strongly influenced by relative humidity of the cells for expediting the proton transfer in the cells.

\section{References}

[1] Y. Wan, K. A. M. Creber, B. Peppley, V. T. Bui, J. Appl. Polym. Sci., vol. 89, pp. 306-317, 2003.

[2] J. Zhang, Y. Tang, C. Song, Z. Xia, H. Li, H. Wang, J. Zhang, "PEM fuel cell relative humidity (RH) and its effect on performance at high temperatures," Electrochim. Acta, vol. 53, pp. 5315-5321, 2008. 